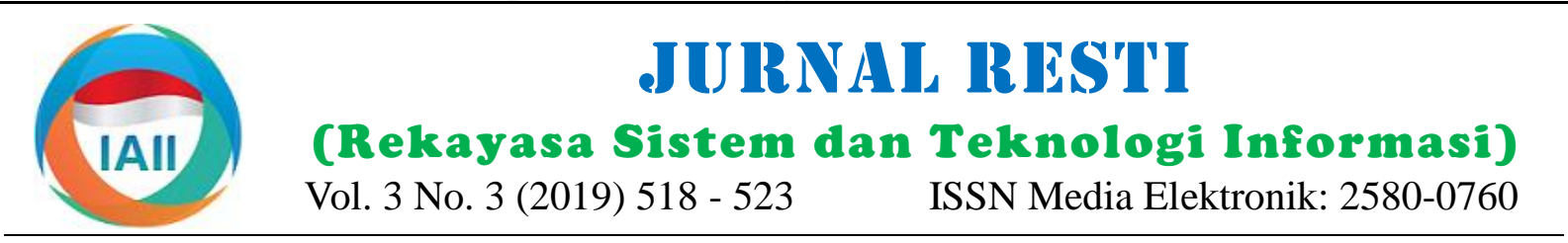

\title{
Sistem Pakar Identifikasi Modalitas Belajar Siswa Menggunakan Metode Forward Chaining
}

\author{
Asep Kurniawan ${ }^{1}$, Sumijan $^{2}$, Jufriadif Na`am ${ }^{3}$ \\ ${ }^{1,2,3}$ Faculty of Computer Science, Universitas Putra Indonesia YPTK Padang \\ ${ }^{1}$ asepkurniawan260991@ gmail.com. ${ }_{2}^{2}$ soe@ upiyptk.org, ${ }^{3}$ jufriadif@yahoo.com
}

\begin{abstract}
Student learning modalities are important to be identified by teachers and students. Because the success of students in the field of academics is supported by the appropriate student learning modalities. Often occurs in the process of teaching and learning teachers do not know the modalities of student learning so that the material in teaching teachers difficult to accept by students. Appropriate learning modalities that are in accordance with the methods taught by the teacher need to be built in an Expert System. Expert System that is processed in this research is taken from the expertise of teachers of Senior High School Counseling Guidance 1 Tilatang Kamang by using Forward Chaining method. Learning modalities are processed using expert systems created with php programming languages and mysql databases. Furthermore, this expert system can determine the modalities of visual learning, auditory and kinesthetic. The result of testing on this method is able to determine the learning modality in the students with the accuracy and the speed is good. Expert system test results have been able to determine student learning modalities clearly and can already be recommended to help teachers and students in improving the way students learn the right.
\end{abstract}

Keywords: Expert system; Learning Modality; Forward Chaining

\begin{abstract}
Abstrak
Modalitas belajar siswa merupakan hal yang penting untuk di identifikasi oleh guru dan siswa. Karena keberhasilan siswa dibidang akademis didukung oleh modalitas belajar siswa yang tepat. Sering kali terjadi dalam proses belajar mengajar guru belum mengetahui modalitas belajar siswa sehingga materi yang di ajarkan guru sulit diterima oleh siswa. Modalitas belajar yang tepat dan sesuai dengan metode yang diajarkan oleh guru perlu dibantu dengan sistem pakar. Sistem Pakar yang diolah dalam penelitian ini diambil dari kepakaran guru Bimbingan Konseling Sekolah Menengah Atas Negeri 1 Tilatang Kamang dengan menggunakan metode Forward Chaining. Modalitas belajar diolah menggunakan sistem pakar yang dibuat dengan bahasa pemograman php dan database mysql. Selanjutnya sistem pakar ini dapat menentukan modalitas belajar visual, auditory dan kinesthetic. Hasil dari pengujian terhadap metode ini adalah dapat menentukan modalitas belajar pada siswa dengan tingkat keakurasian dan kecepatan yang baik. Sistem Pakar hasil pengujian telah dapat menentukan modalitas belajar siswa dengan jelas dan sudah dapat direkomendasikan untuk membantu guru dan siswa dalam meningkatkan cara belajar siswa yang tepat.
\end{abstract}

Keywords: Sistem Pakar; Modalitas Belajar; Forward Chaining

(C) 2019Jurnal RESTI

\section{Pendahuluan}

Modalitas belajar merupakan salah satu karakteristik belajar yang berkaitan dengan menyerap, mengolah, dan menyampaikan informasi [1]. Modalitas belajar yang sesuai adalah kunci keberhasilan siswa dalam belajar. Dengan menyadari hal ini, siswa mampu menyerap dan mengolah informasi dan menjadikan belajar lebih mudah dengan Modalitas belajar siswa sendiri. Penggunaan Modalitas belajar yang dibatasi hanya dalam satu bentuk, terutama yang bersifat verbal atau dengan jalur auditorial, tentunya dapat menyebabkan adanya ketimpangan dalam menyerap informasi. Oleh karena itu, dalam kegiatan belajar, siswa perlu dibantu dan diarahkan untuk mengenali Modalitas belajar yang sesuai dengan dirinya sehingga tujuan pembelajaran dapat dicapai secara efektif.

Dalam gaya belajar terdapat tiga modalitas belajar yaitu visual, auditory, dan kinesthetc [2]. Modalitas belajar

Diterima Redaksi : 15-08-2019 | Selesai Revisi : 15-09-2019 | Diterbitkan Online : 14-12-2019 
seorang siswa dapat dibantu dengan suatu sistem yang penelitian ini diawali dengan mengidentifikasi masalah, mana pengetahuannya di ambil dari seorang pakar guru menganalisa masalah, menentukan tujuan, mempelajari bimbingan konseling. Salah satu sistem yang dapat literatur, pengumpulan data, menganalisa data, desain membantu manusia dalam menentukan keputusan sistem, implementasi sistem dan pengujian terutama dalam mengidentifikasi modalitas belajar sistem.Tahap-tahap kerangka kerja dibuat agar siswa adalah sistem pakar.

Sistem pakar adalah sistem berbasis komputer yang menggunakan pengetahuan, fakta dan teknik penalaran dalam memecahkan masalah yang biasanya hanya dapat dipecahkan oleh seorang pakar dalam bidang 2.1 Basis Pengetahuan

tersebut [3]. Dalam merancang sistem pakar yang baik maka aplikasi yang di rancang harus bisa menyelesaikan berbagai permasalahan dengan mencontoh kerja dan pemikiran para pakar atau para ahli.Dengan adanya Sistem Pakar masyarakat mampu menyelesaikan permasalahan yang sebenarnya hanya bisa diselesaikan dan dikerjakan dengan bantuan para pakar di bidang tertentu.

Forward Chaining merupakan fakta untuk mendapatkan kesimpulan (conclusion) dari fakta tersebut. Penalaran ini berdasarkan fakta yang ada (data driven), dimana metode ini dijalankan dengan mengumpulkan fakta-fakta yang ada untuk menarik kesimpulan [4]. Dengan kata lain, prosesnya dimulai dari facts (fakta-fakta yang ada) melalui proses interface fact (penalaran fakta-fakta) menuju suatu goal (suatu tujuan). Pelacakan maju ini sangat baik dalam mengidentifikasi modalitas belajar siswa karena seluruh proses akan dikerjakan secara berurutan maju.

Forward Chaining merupakan proses yang terurut kedepan dimulai dengan kumpulan data atau fakta yang terpercaya menuju kondisi akhir. Analisanya yakni forward chaining dimulai dari tahapan informasi masukan dikodekan dengan (if) hingga menjadi konklusi (then) [5].

Forward Chaining cocok dipakai untuk menangani permasalahan dalam pengidentifikasian modalitas belajar siswa. Untuk lebih memahami metode ini, berikut contoh ilustrasi kasus Sistem Pakar.

Aturan I:

Jika Premis 1, Dan Premis 11, Dan Premis 11l, Maka Konklusi 1.

Aturan II:

Jika Premis 1, Dan Premis 11, Dan Premis 11l, Maka Konklusi 11 .

Aturan III:

Jika Premis 1, Dan Premis 11, Dan Premislll, Maka Konklusi 111.

\section{Metodologi Penelitian}

Pada metodologi penelitian ini merupakan langkahlangkah kerja, yang perlu dilakukan agar penyusunan penelitian menjadi lebih mudah dan juga dapat digunakan sebagai pedoman dalam melaksanakan penelitian. Adapun bentuk uraian kerangka kerja dalam penelitian menjadi terarah dan mencapai tujuan yang ditentukan dalam penelitian ini.Tujuan penelitian ini yakni untuk mengidentifkasi modalitas belajar siswa menggunakan metode Forward Chaining.

Representasi pengetahuan yang diperoleh dari pakar tersebut adalah berupa data karakter modalitas belajar.Disini data yang di gunakan dan di dapatkan berjumlah 3 macam modalitas serta anjuran dan strategi sesuai dengan modalitas belajar. Adapun karakter modalitas belajar yang diperoleh dari pakar dapat dilihat pada tabel 2 di bawah ini:

Tabel 2. Karakter modalitas

\begin{tabular}{|c|c|c|}
\hline No & Karakter & Modalitas \\
\hline 1 & Mudah mengingat hal yang dilihat & Visual \\
\hline 2 & Mudah mengingat hal yang didengar & Auditory \\
\hline 3 & Mudah mengingat hal yang dilakukan & Kinesthetic \\
\hline 4 & $\begin{array}{l}\text { Suka diajari oleh guru dengan cara } \\
\text { menggambarkan suatu objek di papan tulis }\end{array}$ & Visual \\
\hline 5 & $\begin{array}{l}\text { Suka diajari oleh guru dengan cara } \\
\text { mempraktekkan }\end{array}$ & Kinesthetic \\
\hline 6 & $\begin{array}{l}\text { Suka diajari oleh guru dengan cara } \\
\text { menjelaskan dengan suara yang indah }\end{array}$ & Auditory \\
\hline 7 & $\begin{array}{l}\text { Senang menghafal sesuatu dengan } \\
\text { mengulangi kata-kata dengan suara keras }\end{array}$ & Auditory \\
\hline 8 & $\begin{array}{l}\text { Senang menghafal sesuatu dengan dengan } \\
\text { menulis }\end{array}$ & Visual \\
\hline 9 & Senang menghafal sesuatu sambil berjalan & Kinesthetic \\
\hline 10 & Berbicara dengan tempo cepat & Visual \\
\hline 11 & Berbicara dengan tempo sedang & Auditory \\
\hline 12 & Berbicara dengan tempo lambat & Kinesthetic \\
\hline 13 & $\begin{array}{l}\text { Dalam menjelaskan sesuatu, saya cendrung } \\
\text { menggerakkan tangan }\end{array}$ & Kinesthetic \\
\hline 14 & $\begin{array}{l}\text { Dalam menjelaskan sesuatu, saya } \\
\text { menyampaikan dengan baik }\end{array}$ & Auditory \\
\hline 15 & $\begin{array}{l}\text { Dalam menjelaskan sesuatu, saya cendrung } \\
\text { membuat coretan dikertas }\end{array}$ & Visual \\
\hline 16 & Sulit kosentrasi ketika ada keributan & Auditory \\
\hline 17 & $\begin{array}{l}\text { Sulit kosentrasi ketika yang dilihat tidak } \\
\text { rapi }\end{array}$ & Visual \\
\hline 18 & $\begin{array}{l}\text { Sulit konsentrasi ketika duduk diam dan } \\
\text { tenang }\end{array}$ & Kinesthetic \\
\hline 19 & Sangat menyukai lukisan & Visual \\
\hline 20 & Sangat menyukai tarian atau Silat & Kinesthetic \\
\hline 21 & Sangat menyukai musik & Auditory \\
\hline 22 & $\begin{array}{l}\text { Cendrung memperhatikan orang pada } \\
\text { wajah dan pakaiannya }\end{array}$ & Visual \\
\hline 23 & $\begin{array}{l}\text { Cendrung memperhatikan prilaku dan } \\
\text { gerak gerik orang }\end{array}$ & Kinesthetic \\
\hline 24 & $\begin{array}{l}\text { Cendrung memperhatikan pada } \\
\text { pembicaraan orang }\end{array}$ & Auditory \\
\hline 25 & Suka praktek langsung dalam merakit alat & Kinesthetic \\
\hline 26 & $\begin{array}{l}\text { Suka baca alur kerja sebelum merakit alat- } \\
\text { alat }\end{array}$ & Visual \\
\hline 27 & $\begin{array}{l}\text { Suka mendengarkan penjelasan sebelum } \\
\text { merakit alat-alat }\end{array}$ & Auditory \\
\hline 28 & $\begin{array}{l}\text { Selama waktu luang saya paling suka pergi } \\
\text { ke perpustakaan }\end{array}$ & Visual \\
\hline 29 & $\begin{array}{l}\text { Selama waktu luang saya paling suka } \\
\text { mendengarkan musik }\end{array}$ & Auditory \\
\hline
\end{tabular}


30 Selama waktu luang saya paling suka Berolahraga atau mengerjakan apa saja Fokus pada kata - kata atau gambar di depan saya

32 Mendiskusikan masalah dan penyelesaian yang mungkin dalam pikiran

33 Banyak bergerak, menggesek - gesekkan pensil, atau menyentuh sesuatu

34 Menulis banyak catatan revisi dan diagram Membahas catatan saya, sendiri atau dengan orang lain

36 Membayangkan membuat gerakan atau menciptaan rumus

Membaca catatan, membaca judul dan sub-

37 judul dalam buku dan melihat diagram dan ilustrasi

Meminta seseorang memberi anda

38 pertanyaan, atau menghafal dalam hati sendiri

39 Membuat catatan pada kartu dan membuat diagram

Melihat sekeliling museum dan

40 menemukan peta yang menunjukkan lokasi berbagai benda yang di pamerkan

Berbicara dengan penjaga museum dan

41 bertanya kepadanya tentang benda - benda yang di pamerkan

Melihat pada benda pertama yang kelihatan

2 menarik di museum, dan baru kemudian membaca petunjuk lokasi benda -benda lainnya

43 Menonton film tentang cara kerja komputer

44 Mendengarkan seseorang menjelaskan cara kerja komputer

Membongkar komputer dan mencoba

45

menemukan sendiri cara kerjanya

Anjuran modalitas belajar yang diperoleh dari pakar dapat dilihat pada tabel 3.

Tabel 3.Anjuran Modalitas

\begin{tabular}{clc}
\hline No & \multicolumn{1}{c}{ Anjuran Siswa } & Modalitas \\
\hline 1 & $\begin{array}{l}\text { Ucapkanlah apa yang sedang kamu baca } \\
\text { sehingga terdengar agar kamu mudah } \\
\text { mengingatnya }\end{array}$ & Auditory \\
& $\begin{array}{l}\text { Buatlah coretan di kertas setiap kali } \\
\text { kamu menghafal sesuatu dan mencatat }\end{array}$ & \\
2 & $\begin{array}{l}\text { segala informasi yang kamu dengar } \\
\text { seperti dari guru agar kamu mudah }\end{array}$ & \\
& mengingatnya & \\
& $\begin{array}{l}\text { Agar bisa menghafal sesuatu dan mudah } \\
\text { mengingatnya lakukanlah dengan } \\
\text { menngerakkan sesuatu atau sambil }\end{array}$ & Kinesthetic \\
berjalan selama itu tidak mengganggu & \\
& orang lain. &
\end{tabular}

Strategi modalitas belajaryang diperoleh dari pakar dapat dilihat pada tabel 4 .

Tabel 4. Strategi Modalitas

\begin{tabular}{clc}
\hline No & \multicolumn{1}{c}{ Strategi Guru } & Modalitas \\
\hline 1 & $\begin{array}{l}\text { Gunakan variasi vokal dan suara yang } \\
\text { jelas saat mengajar }\end{array}$ & Auditory \\
2 & $\begin{array}{l}\text { Gunakan media pembelajaran yang } \\
\text { menarik saat mengajar }\end{array}$ & Visual \\
3 & $\begin{array}{l}\text { Gunakan gerakan tubuh dan praktek saat } \\
\text { mengajar }\end{array}$ & Kinesthetic \\
\hline
\end{tabular}

Auditory

Kinesthetic

Visual

Auditory

Kinesthetic

Visual

Auditory

Kinesthetic

\subsection{Inference Engine ( Mesin inferensi )}

Teknik yang digunakan dalam perancangan sistem pakar ini menggunakan metode forward chaining atau biasa juga disebut inferensi maju.Metode ini dipilih karena metode ini lebih cocok di terapkan untuk memperoleh hasil identifikasi modalitas belajar. Pengumpulan data dilakukan dengan cara melihat karakter modalitas belajar hingga memperoleh suatu kesimpulan dari permasalahan-permasalahan yang ada serta anjuran untuk siswa dan strategi untuk guru.

Dari hasil analisa data dengan menggunakan metode forward chaining diatas maka bisa dibuatkanflowchartseperti gambar 2.

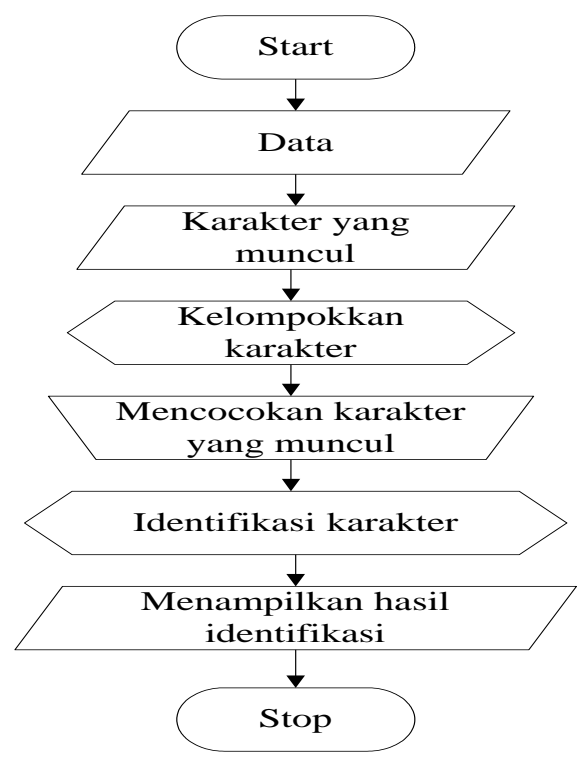

Gambar 2.Flowchart Metode Forward Chaining

Flowchart di atas telah diimplementasikan kedalam bahasa pemrograman PHP dengan menggunakan database MySQL, berikut urutan prosesnya:

A. Data

Untuk mendapatkan informasi dan data-data yang valid maka di lakukan wawancara dengan Pakar Guru Bimbingan Konseling yang dilakukan di SMAN 1 Tilatang Kamang.

B. Karakter yang muncul

Karakter sebagaimana yang telah dijelaskan pada sub bab4.1

C. Pengelompokkan karakter

Berdasarkan variabel yang ada diatas modalitas dan karakternya maka bisa dikelompokkan berdasarkan penalaran beberapa modalitas melalui pohon keputusan. LihatGambar 3.

D. Pencocokan Karakter yang muncul

Dari pengelompokan diatas dilalukan pencocokan pada karakter dan modalitas dengan membuat tabel decision berikut ini: 


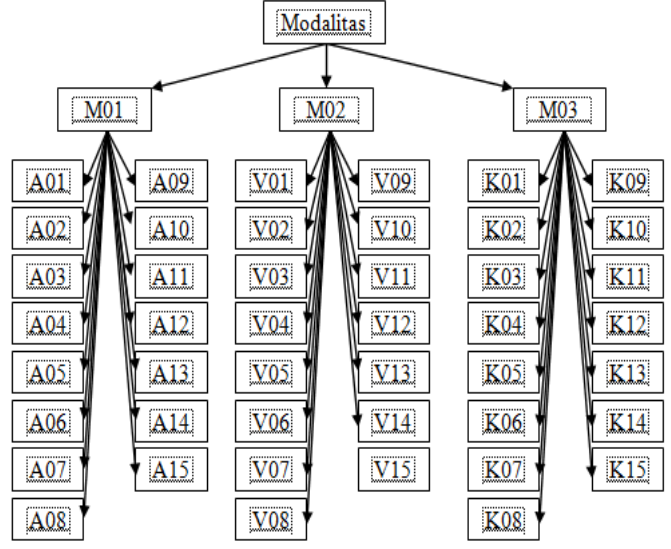

Gambar 3.Pohon Keputusan Modalitas

Tabel 5.Decision Tabel Identifikasi Modalitas Belajar

\begin{tabular}{|c|c|c|c|c|}
\hline No & Kode & M01 & M02 & M03 \\
\hline 1 & V01 & & $X$ & \\
\hline 2 & A01 & $\mathrm{X}$ & & \\
\hline 3 & K01 & & & $X$ \\
\hline 4 & V02 & & $X$ & \\
\hline 5 & $\mathrm{~A} 02$ & $X$ & & \\
\hline 6 & K02 & & & $X$ \\
\hline 7 & V03 & & $X$ & \\
\hline 8 & K03 & & & $X$ \\
\hline 9 & A03 & $X$ & & \\
\hline 10 & V04 & $\mathrm{X}$ & & \\
\hline 11 & K04 & & $X$ & \\
\hline 12 & A04 & & & $X$ \\
\hline 13 & K05 & & & $X$ \\
\hline 14 & A05 & $X$ & & \\
\hline 15 & V05 & & $X$ & \\
\hline 16 & A06 & $\mathrm{X}$ & & \\
\hline 17 & V06 & & $X$ & \\
\hline 18 & K06 & & & $X$ \\
\hline 19 & V07 & & $X$ & \\
\hline 20 & K07 & & & $X$ \\
\hline 21 & A07 & $X$ & & \\
\hline 22 & V08 & & $X$ & \\
\hline 23 & K08 & & & $X$ \\
\hline 24 & A08 & $X$ & & \\
\hline 25 & K09 & & & $X$ \\
\hline 26 & V09 & & $X$ & \\
\hline 27 & A09 & $X$ & & \\
\hline 28 & V10 & & $X$ & \\
\hline 29 & A10 & $X$ & & \\
\hline 30 & K10 & & & $X$ \\
\hline 31 & V11 & & $X$ & \\
\hline 32 & A11 & $X$ & & \\
\hline 33 & K11 & & & $X$ \\
\hline 34 & V12 & & $X$ & \\
\hline 35 & $\mathrm{~A} 12$ & $X$ & & \\
\hline 36 & K12 & & & $X$ \\
\hline 37 & V13 & & $X$ & \\
\hline 38 & A13 & $X$ & & \\
\hline 39 & K13 & & & $X$ \\
\hline 40 & V14 & & $X$ & \\
\hline 41 & A14 & $X$ & & \\
\hline 42 & K14 & & & $X$ \\
\hline 43 & V15 & & $X$ & \\
\hline 44 & A 15 & $X$ & & \\
\hline 45 & K15 & & & $X$ \\
\hline
\end{tabular}

E. Hasil Identifikasi

Berdasarkan penyajian fakta dan proses yang sudah dijelaskan di atas, untuk perancangan dan perencanaan identifikasi modalitas belajar, maka disusun daftar aturan (rule) yang sesuai dengan prosedur dengan menggunakan ekspresi logika, untuk lebih jelasnya dapat dilihat pada tabel di bawah ini:

Tabel 6. Daftar Aturan (Rule)Identifikasi Modalitas Belajar

\begin{tabular}{ll}
\hline No & Aturan (Rule) karakter dengan modalitas \\
\hline $\mathbf{1}$ & If Karakter A01 and A02 and A03 and A04 and A05 and \\
& A06 and A07 and A08 and A09 and A10 and A11 and A12 \\
and A13 and A14 and A15 then modalitas auditory (M01) \\
$\mathbf{2}$ & If Karakter V01 and V02 and V03 and V04 and V05 and \\
& V06 and V07 and V08 and V09 and V10 and V11 and V12 \\
& and V13 and V14 and V15 then modalitas visual (M02) \\
$\mathbf{3}$ & If Karakter K01 and K02 and K03 and K04 and K05 and \\
& K06 and K07 and K08 and K09 and K10 and K11 and K12 \\
and K13 and K14 and K15 then modalitas kinesthetic \\
(M03)
\end{tabular}

\section{Hasil dan Pembahasan}

Dalam implementasi sistem diperlukan aplikasi Sistem Pakar untuk mengidentifikasi modalitas belajar dengan menggunakan bahasa pemrograman PHP dan database MySQL.

\subsection{Tampilan Halaman Utama}

Pada form halaman utama terdiri dari 3 bagian pengguna yaitu admin sebagai pengelola aplikasi, guru untuk melihat hasil identifikasi modalitas belajar siswa dan siswa sebagai pengguna aplikasi. Sebelum siswa dapat menggunakan aplikasi, siswa harus melakukan registrasi pada menu pendaftaran. Hal ini berguna bagi siswa untuk mendapatkan username dan password. Setelah siswa mendapatkan username dan password, siswa dapat login ke sistem, di mana pada form menu utama siswa ada beberapa menu seperti menu modalitas dan menu konsultasi.

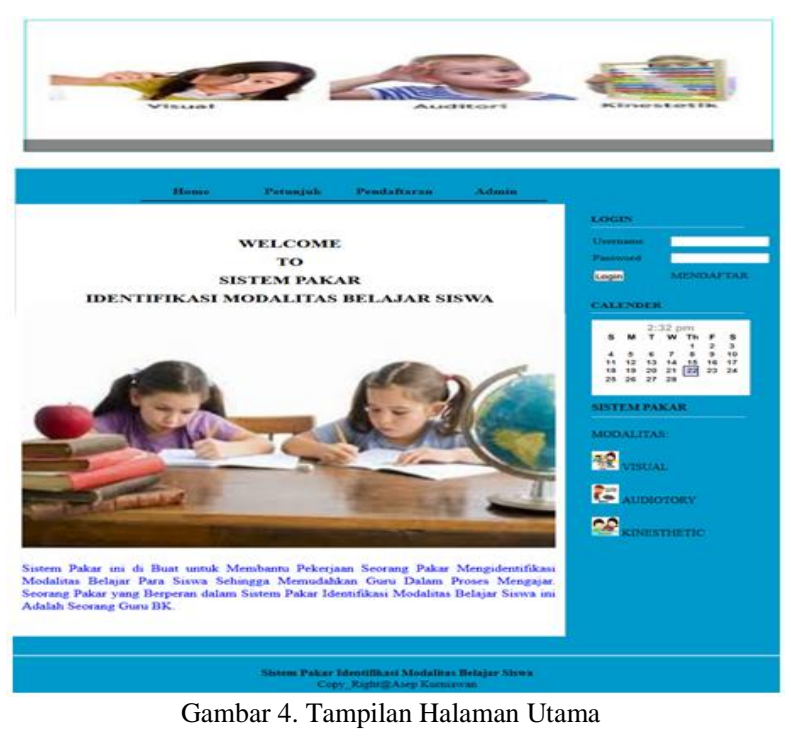

\subsection{Tampilan Menu Pendafataran}

Pada gambar 5 di bawah adalah tampilan form registrasi pendaftaran siswa, seperti yang sudah 
dijelaskan di atas, menu registrasi berguna bagi siswa untuk mendapatkan username dan password.

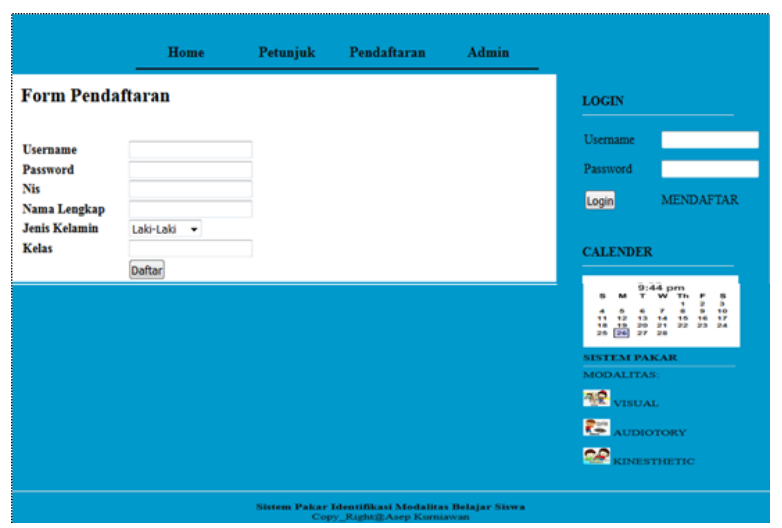

Gambar 5. Tampilan Menu Pendaftaran

\subsection{Tampilan Halaman Utama Siswa}

Pada gambar 6 di bawah ini adalah tampilan halaman utama siswa setelah melakukan login yang terdiri dari menu info, menu identifikasi, menu laporan, menu petunjuk dan menu logout untuk keluar halaman utama siswa.

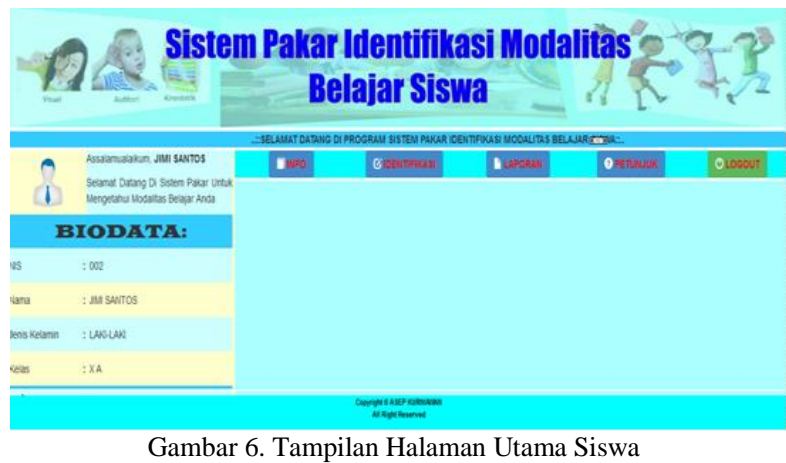

\subsection{Tampilan Menu Identifikasi}

Menu Identifikasi merupakan tampilan interaksi antara siswa dengan sistem dalam melakukan identifikasi modalitas belajar.Ada beberapa pertanyaan yang diajukan oleh sistem yang berhubungan dengan karakter modalitas belajar dan selanjutnya siswa menjawab pertanyaan dengan menceklist sesuai dengan fakta-fakta karakter siswa yang ditemukan. Kemudian siswa akan mengklik tombol identifikasi, sepeti terlihat pada gambar 7 berikut.

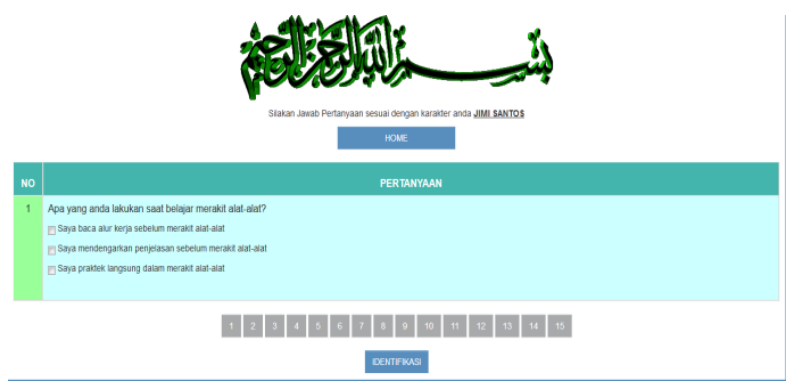

Gambar 7.Tampilan Menu Identifikasi
Setelah beberapa pertanyaan yang diajukan sistem sudah dijawab oleh siswa, selanjutnya siswa akan mengklik tombol identifikasi maka akan tampil hasil identifikasi, seperti terihat pada gambar 8 berikut.

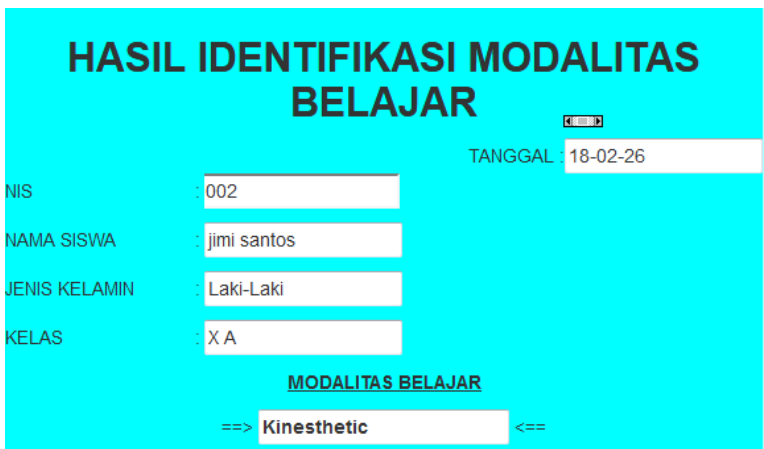

Anda memiliki modalitas belajar Kinesthetic, yang mengharuskan anda untuk menyentu sesuatu yang memberikan informasi tertentu agar anda bisa mengingatnya. Tentu saja ad beberapa karakteristik model belajar seperti ini yang tak semua orang bisa melakukannya Karakter pertama adalah menempatkan tangan sebagai alat penerima informasi utama agar bisa terus mengingatnya. Hanya dengan memegangnya saja, anda bisa menyerap informasi tanpa harus membaca penjelasannya

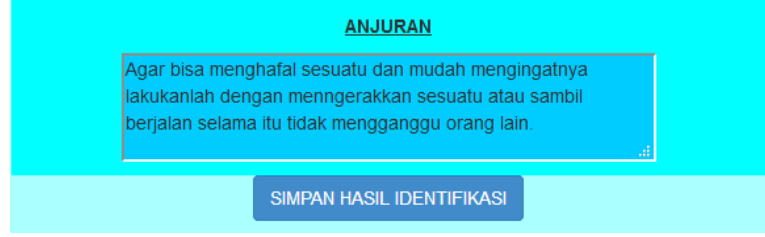

Gambar 8. Tampilan Menu Hasil Identifikasi

Setelah tampil hasil identifikasi kemudian klik tombol simpan hasil identifikasi untuk menyimpan hasil identifikasi ke database, kemudian akan tampil ke menu laporan.

\subsection{Tampilan Menu Laporan}

Pada gambar 9 berikut ini adalah tampilan form laporan yang berisi hasil identifikasi modalitas belajar siswa dan anjuran belajar yang sudah tersimpan ke database dan terdapat tombol print untuk mencetak hasil identifikasi.

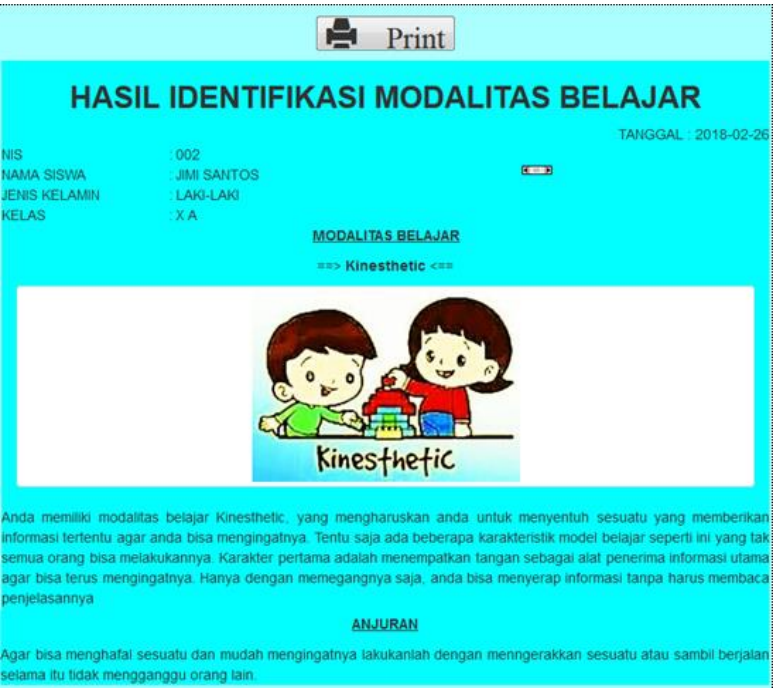

Gambar 9. Tampilan Menu Laporan

Jurnal RESTI (Rekayasa Sistem dan Teknologi Informasi) Vol. 3 No.3 (2019) 518- 523 
Hasil uji coba yang dilakukan kepada 10 orang siswa dengan menggunakan aplikasi Sistem Pakar ini 8 orang hasil modalitas belajarnya sesuai dengan karakteristik belajar siswa.

\section{Kesimpulan}

Berdasarkan penelitian dan pembahasan yang dilakukan dalam mengidentifikasi modalitas belajar, maka dapat disimpulkan bahawa Sistem Pakar dengan Metode Forward Chaining ini telah mampu mengidentifikasi modalitas belajar siswa dengan jelas tanpa harus berkonsultasi dengan pakar atau guru Bimbingan Konseling di sekolah dan Sistem Pakar ini dapat memberikan gambaran jenis modalitas belajar serta anjuran cara belajar untuk siswa dan strategi mengajar untuk guru, sehingga Sistem Pakar ini sudah dapat direkomendasikan untuk membantu guru dan siswa dalam meningkatkan cara belajar siswa yang tepat.

\section{Daftar Rujukan}

[1] Soewono, R., 2014. Sistem Pakar Identifikasi Modalitas Belajar dengan Implementasi Algoritma C4.5. Jurnal Sistem Informasi Bisnis, pp.20-27.
[2] Sari, A.K.,2014.Analisis karakteristik gaya belajar vak(visual, Auditorial, kinestetik)mahasiswa pendidikan Informatika. Jurnal Ilmiah Edutic,pp1-11.Vol 1. No 1.

[3] Gilakjani, A.P.,2012.Visual, Auditory, Kinaesthetic Learning Styles and Their Impacts on English Language Teaching. Journal of Studies in Education, pp.104-113, Vol. 2, No. 1.

[4] Kesumaningtyas,F.,2017.Sistem pakar diagnosa penyakit demensia menggunakan metode forward chaining. Jurnal Edik Informatika.pp.95-102. V3.i2

[5] Supartini.W., dan Hindarto. Sistem Pakar Berbasis Web Dengan Metode Forward Chaining Dalam Mendiagnosis Dini Penyakit Tuberkulosis di jawaTimur.KINETIK, Vol.1, No.3.pp.147-154.

[6] Budiharto dan Suhartono.,2014.Atificial Intelligence konsep dan penerapannya. CV. Andi Offset.

[7] Lucy,B.,2009. Mendidik Sesuai Dengan Bakat Dan Minat Anak, ( Jakarta : Tangga Pustaka, Hal 114

[8] Saputra.,D,Lestari.,U dan Sutanta.,E,2015.Sistem Pakar untuk Diagnosa Penyakit Kucing Berbasis Web Menggunakan Framework Codeigniter.Jurnal SCRIPT.pp29-38. Vol.3, No.1.

[9] Hadi.M, Misdram.M., dan Aini,R.A.,2016.Perancangan Sistem Pakar Diagnosa Penyakit Ayam Dengan Metode Forward Chaining. Jurnal Informatika Merdeka Pasuruan.pp.111139.Vol.2, No. 1 .

[10] Soewono, Gernowo dan Sasongko.2014.Sistem Pakar Identifikasi Modalitas Belajar Siswa Dengan Implementasi Algoritma C4.5.Jurnal Sistem Informasi Bisnis,.pp.20-27.

[11] Arylien Ludji Bire, dkk (2014), "Pengaruh Gaya Belajar Visual, Audiotorial, Dan Kinestetik Terhadap Prestasi Belajar Siswa”. Jurnal Kependidikan 44:168-174.

[12] Junierissa Marpaung. (2015). "Pengaruh Gaya Belajar Terhadap Prestasi Belajar Siswa”, Jurnal KOPASTA 2:82-86. 